\title{
EXAMINING ADULT'S IDENTITY STATUSES: ADAPTIVE VS. MALADAPTIVE DIMENSION
}

\author{
Maia Mestvirishvili, Natia Mestvirishvili, \\ Khatuna Martskvishvili, Luiza Arutinov \\ Ivane Javakhishvili Tbilisi State University, Georgia \\ E-mail: mmestvirishvili@gmail.com, Natia.mestvirishvili@gmail.com
}

\begin{abstract}
To achieve the status of ego identity remains the most important challenge for the adolescence period and consequently is a challenge for developmental psychologists too. The vast majority of studies focus on understanding the dynamics of ego identity development, however, factors that cause different path of development remained unclear. This study aims at tracking the paths, which differentiate ego statuses from finding psychosocial factors contributing to ego identity achievement.

For this purpose the relationships between four identity statuses - achievement, exploration, moratorium and foreclosure and number of psychosocial variables such as attachment style, self-esteem and perfectionism have been examined. 386 school teenagers aged 14-17 $(M=15.48)$ filled a set of questionnaires comprised of four instruments: The Ego Identity Process Questionnaire (EIPQ), The Measure of Attachment Qualities (MAQ), The Perfectionism Inventory (PI) and Adult Sources of Self-Esteem Inventory (ASSEI). Discriminant analysis revealed two basic dimensions (adaptive and maladaptive), which are capable to depict the difference between ego identity statuses. The first discriminant function of ego identity status is primarily defined by conscientious perfectionism and secured attachment; whereas, the second discriminant function consists of avoidance attachment, self-evaluative perfectionism and ambivalent attachment styles. Key words: adolescence period, ego identity status, ego identity development, psychosocial factors.
\end{abstract}

\section{Introduction}

Adolescence is a period that is associated with the most important decisions, which individuals make in their lives. This is the period for adolescents when they have to define their values, social roles and responsibilities; and, they have to evaluate their personal potential. The most challenging for the youth is to achieve the ego-identity in the way of self-exploration and self-commitment.

Ego identity is the result of complex psychosocial influences, which starts from early childhood and continues until the late adolescent period. A model developed my Marcia (1966) differentiates four identity statuses: Identity Achievement, Identity Diffusion, Identity Moratorium and Identity Foreclosure.

Marcia Ego-Identity Status Theory is the theoretical model of the ego-identity process. The ego-identity style covers two concepts: exploration and commitment (Marcia, 1966 - cited in Kroger \& Marcia, 2011). The exploration process implies reevaluation of values, attempting and 
seeking for different roles, goals and experiences. Commitment to the behavior and values is an individual's own sense of engagement (Kroger \& Marcia, 2011). Their combination gives four different identity statuses: Identity Achievement, Identity Diffusion, Identity Moratorium and Identity Foreclosure (Balistreri, Busch-Rossnagel, \&Kiesinger, 1995).

In case of identity achievement status, there is a high level of commitment as well as exploration (Kroger \& Marcia, 2011). This status represents the final point of identity, when an individual has balanced thinking, effective decision-making abilities and deep interpersonal relationships (Schwartz et al., 2011). The Individual is flexible, but his or her life positions do not change under the influence of external impact or press (Kroger \& Marcia, 2011). A sense of one's own integrity determines the ability of understanding and sharing of others' positions and experiences (Kroger \& Marcia, 2011), which in turn leads to the ability of having deep interpersonal relationships (Schwartz et al., 2011).

Moratorium implies decision-making process, but without taking responsibility. It is associated with critical thinking and with the process of developing alternatives (Schwartz et al., 2011). Individuals in moratorium are actively exploring, attempting and discussing different new ideas and values (Kroger \& Marcia, 2011) They are characterized by global and changing point of views (Schwarz, 2011) and often are morally sensitive (Kroger \& Marcia, 2011)

In identity foreclosure, individuals take responsibilities without conscious decision (Schwartz et al., 2011). They look strong and have a high sense of control as individuals of identity achievement status, but they have trouble in discussing alternatives (Kroger \& Marcia, 2011). In case of having, adequate values that are relevant to the certain social context, these individuals do not have difficulties, but if they lose the safe environment, they are in crisis (Schwartz et al., 2011). Individuals in identity foreclosure are characterized by authoritarianism. However, it should be mentioned that they have idealized, conflict-free relationships with parents (Schwartz et al., 2011).

In identity, diffusion is a low level of commitment and decision-making. Individuals in this status are often apathetic and do not show any interest. They have trouble in the form of maladaptive results, like difficulties in learning. They don't get social feedback and often are depressive (Schwartz et al., 2011).

There is no single view about what are the most influential factors that contribute to the identity crisis resolution and lead to the successful path from identity crisis to identity achievement. Socialization of a child begins with formation of attachment style, which is capable to predict social, emotional and personal life of individuals. Later, in the period of early adolescence, selfrelated beliefs and attitudes are established and consequently a sense of self-esteem is formed. Self-esteem plays a crucial role in their motivations and accomplishments and consequently we assume that it affects the process of formation of ego identity. Adolescents are sometimes at the risk to develop perfectionism, pursue unrealistic goals, and be deeply stressed when they did not meet high standards. Scientific literature does not say anything about how perfectionism affects the process of ego identity achievement. In our study, we explore attachment styles, self-esteem and perfectionism in the context of ego identity statuses, and try to understand whether ego identity statuses vary according to those variables.

\section{Methodology of Research}

Quantitative study has been designed to explore the relationship between four ego identity statuses and psychosocial variables: attachment styles, perfectionism and self-esteem. For each variable, the most relevant and highly valid instruments were chosen. Each of these questionnaires has gone through the process of translational and back translation and pilot study.

\section{Study Participants}

Study sample consists of 14-18 years old 386 high school students (208 girls and 178 boys). The mean age of the sample was 15,48 with a standard deviation of 1.07 .8 th and 9 th grade students were $37.1 \%$ of the whole sample and 10th, 11 th and 12 th graders were $62.9 \%$. The participants were asked to report their academic achievement, which was measured by calculating average mark 
of all subjects of the past semester. The mean score of the sample measuring academic achievement was 8.1 with standard deviation 1.16 (students are graded on a 10 point scale in Georgian schools).

\section{Instrument and Procedures}

Ego identity process Questionnaire. In order to assess the status of ego identity process, we used the Ego Identity Process Questionnaire (EIPQ; Balistreri et al. 1995). This instrument consists of 32 items reflecting two dimensions of ego identity process: exploration and commitment. Each item refers to the participants' actual state of being in the process of commitment and exploration of differed domains of life, such as profession, religion, political beliefs, values, gender role, family and friends. According to the instructions of the authors (Balistreri et al.), the study used median split in order to calculate identity statuses. With the combination of low vs. high scores on exploration and commitment, four identity status categories were formed: diffusion, foreclose, achievement and moratorium (see Figure 1).

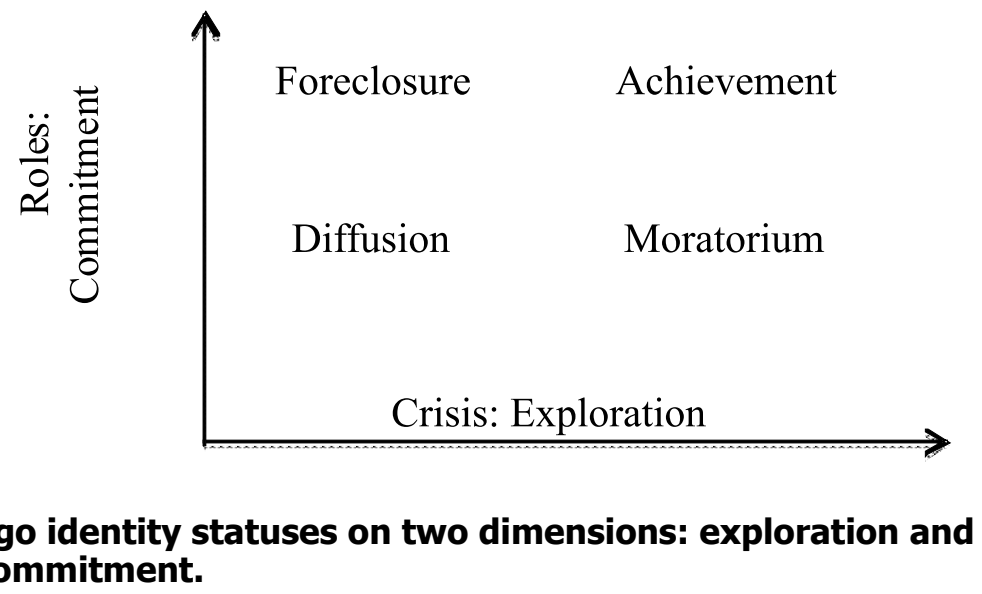

\section{Figure 1: Ego identity statuses on two dimensions: exploration and commitment.}

Attachment styles. We used The Measure of Attachment Qualities (MAQ) developed by Carver (1997) to define the attachment style of the participants. This instrument differentiates four attachment styles: secured attachment, avoidant attachment, and ambivalence-worry attachment and ambivalence-merger attachment styles. The participants evaluated each statement on a Likert style scale: from 1 (do not agree at all) to 5 (fully agree).

Perfectionism. We used perfectionism questionnaire developed by Hill et al., 2004. It consists of 59 items measuring two different styles of perfectionism: conscientious perfectionism and selfevaluative perfectionism. Conscientious perfectionism (Cronbach's alpha 0.842) is an adaptive form of perfectionism and consists of four subscales: high standards for others, organization, plan fullness and striving for excellence. Self-evaluative perfectionism (Cronbach's alpha 0.882) is considered as less adaptive form of perfectionism, which has a negative rather than positive impact on individuals' life. It is measured on four subscales: concern over mistakes, need of approval, perceived parental pressure, and rumination.

Self -esteem. Adult Sources of Self-Esteem Inventory (ASSEI, Fleming \&Elovson, 1988) were developed to measure how important are various aspects of self for individuals and whether or not they are satisfied with the same aspects of self. Consequently, there are two blocks of questionnaires. Each consists of 20 aspects of self to be evaluated on their importance to self-esteem and their satisfaction with these aspects. The score of self-esteem is calculated by subtracting self-satisfaction score to self-importance score.

The study was conducted in high schools during class times. The duration and the purpose of the study were previously negotiated with the school administration and teachers. The participants got the questionnaires along with a short instruction. All questionnaires were administered during one class session and were returned by the end of the session. 


\section{Results of Research}

Independent sample $\mathrm{t}$ test indicates that scores on moratorium status were significantly higher for girls $(\mathrm{M}=0.31, \mathrm{SD}=0.46)$ than for boys $(\mathrm{M}=0.21, \mathrm{SD}=0.41), t(370)=2.1, p=.03, d f=384$. In contrast scores on foreclosure status are higher for boys $(\mathrm{M}=0.39, \mathrm{SD}=0.50)$ than for girls $(\mathrm{M}=0.28$, $\mathrm{SD}=0.45), \quad t(370)=2.39, p=0.01, d f=384$.

A one-way between subjects ANOVA was conducted to explore the impact of ego identity style on levels of perfectionism, attachment and self-esteem. There was a statistically significant difference at $\mathrm{p}<0.00$ level between all variables across the four ego identity styles' groups (See Table 1). Post hoc comparisons using the Tukey HSD test indicated that the mean scores for conscientious and self-evaluative perfectionism are higher in an identity achievement status group than in identity diffusion and moratorium groups $\left(F(3.372)=11.64 ; \eta_{p}{ }^{2}=0.086, p=0.00\right)$. Identity achievements group has also a higher level of secure attachment than all other three groups $(\mathrm{F}$ $\left.(3.373)=6.88 ; \eta_{\mathrm{p}}{ }^{2}=0.052, \mathrm{p}=0.00\right)$. Identity diffusion and moratorium groups differ from each other by the level of self-esteem: the latter has a significantly lower level of self-esteem than identity diffusion group $\left(\mathrm{F}(3.869)=3.27 ; \eta_{\mathrm{p}}^{2}=0.026, \mathrm{p}=0.00\right)$.

Table 1. Participants' mean scores on perfectionism, attachment and selfesteem by identity status groups.

\begin{tabular}{lcccccc}
\hline & $\begin{array}{c}\text { Conscientious } \\
\text { Perfectionism }\end{array}$ & $\begin{array}{c}\text { Self-Evaluative } \\
\text { Perfectionism }\end{array}$ & $\begin{array}{c}\text { Secured } \\
\text { Attachment }\end{array}$ & $\begin{array}{c}\text { Avoidance } \\
\text { Attachment }\end{array}$ & $\begin{array}{c}\text { Ambivalence- } \\
\text { merger } \\
\text { attachment }\end{array}$ & $\begin{array}{c}\text { Self- } \\
\text { esteem }\end{array}$ \\
\hline $\begin{array}{l}\text { 1. Identity } \\
\text { achievement }\end{array}$ & $3.74(2,3)$ & $3.51(2,3,4)$ & $4.20(2.3 .4)$ & $2.96(4)$ & 2.50 & -0.16 \\
$\begin{array}{l}\text { 2. Identity } \\
\text { Diffusion }\end{array}$ & $3.36(1,4)$ & $3.13(1)$ & $3.68(1)$ & 2.80 & 2.53 & $-0.15(3)$ \\
$\begin{array}{l}\text { 3. Identity } \\
\text { Moratorium }\end{array}$ & $3.44(1.4)$ & $3.28(1)$ & $3.85(1)$ & 2.90 & $2.71(4)$ & $-0.33(2)$ \\
$\begin{array}{l}\text { 4. Identity } \\
\text { Foreclosure }\end{array}$ & $3.63(2.3)$ & $3.25(1.2 .3)$ & $3.88(1)$ & $2.75(1)$ & $2.35(3)$ & -0.20 \\
Eta Squared & .086 & .053 & .052 & .023 & .024 & .026 \\
df. & 3.372 & 3.370 & 3.373 & 3.374 & 3.374 & 3.369 \\
F & 11.64 & 6.91 & 6.88 & 2.92 & 3.07 & 3.27 \\
Sig. & .00 & .00 & .00 & .03 & .00 & .00 \\
\hline
\end{tabular}

\section{Discriminant Analysis}

Discriminant analysis was used to conduct a multivariate analysis of variance to determine whether the four identity statuses differ significantly on a linear combination of seven variables: secured attachment, avoidance attachment, ambivalence-worry attachment, ambivalence-merger attachment, conscientious perfectionism, self-evaluative perfectionism and self-esteem.

The findings reveal three descriptive discriminant functions within four groups' results. Two discriminant functions were statistically significant while the third was not $(\mathrm{p}=0.314)$. For the first discriminant function, a Chi-square test was significant (Wilks $\lambda=0.799$, Chi-square $=79.565, \mathrm{df}$ $=21$, Canonical correlation $=0.381, \mathrm{p}<0.00$ ). The second function was also significant (Wilks $\lambda$ $=0.935$, Chi-square $=23.942, \mathrm{df}=12$, Canonical correlation $=0.222, \mathrm{p}<0.03)$, suggesting that differences between four ego identity statuses can be best described with two discriminant functions. Table 2 presents the standardized discriminant function and structure coefficients for two discriminative factors. 
Table 2. Summary of discriminant analysis.

\begin{tabular}{|c|c|c|c|c|c|c|c|c|}
\hline & \multirow[t]{2}{*}{ IA } & \multirow{2}{*}{\multicolumn{2}{|c|}{$\begin{array}{c}\text { ID IM } \\
\text { Group means }\end{array}$}} & \multirow[t]{2}{*}{ IF } & \multicolumn{2}{|c|}{$\begin{array}{c}\text { Standardized } \\
\text { Discriminant } \\
\text { Coefficient }\end{array}$} & \multicolumn{2}{|c|}{$\begin{array}{l}\text { Structure } \\
\text { Coefficient }\end{array}$} \\
\hline & & & & & $\mathrm{F} 1$ & F2 & $\mathrm{F} 1$ & F2 \\
\hline Conscientious Perfectionism & & & & & .627 & -.525 & $.750^{*}$ & -.155 \\
\hline Secured Attachment & & & & & .256 & .472 & $.537^{\star}$ & .407 \\
\hline Avoidance Attachment & & & & & .467 & .376 & .113 & $.645^{*}$ \\
\hline Self-Evaluative Perfectionism & & & & & .078 & .477 & .492 & $.557^{*}$ \\
\hline Ambivalence-merger attachment & & & & & .078 & -.017 & -217 & $.495^{*}$ \\
\hline Ambivalence-worry attachment & & & & & -.478 & .285 & .069 & $.215^{*}$ \\
\hline Self-esteem & & & & & .182 & -.162 & .191 & -.359 \\
\hline \multicolumn{9}{|l|}{ Group centroids } \\
\hline $\mathrm{F} 1$ & .628 & -.496 & -.347 & .165 & & & & \\
\hline F2 & .222 & -.095 & .238 & -.267 & & & & \\
\hline
\end{tabular}

Standardized discriminant function coefficients are indicators of the potential discriminant power for each predictor variable; they may be interpreted similar to beta weights indicating the unique contribution of each predictor variable to the discriminant functions. Structure coefficients show correlations between predictor variables and derived discriminant functions and help to designate and interpret the attributes of discriminant functions.

Examination of the structure coefficient matrix revealed that the first discriminant function of ego identity status is primarily defined by conscientious perfectionism and secured attachment. Identity achievement status group score is higher on this dimension (.63), followed by identity foreclosure (.16). Negative scores have been revealed by the identity moratorium (-.35) and identity diffusion (-.496) status groups - they characterized by a low level of conscientious perfectionism and secure attachment. This cluster of variables we interpreted as 'adaptive dimension', while the variables composing it are positive and adaptive qualities (See Figure 2).

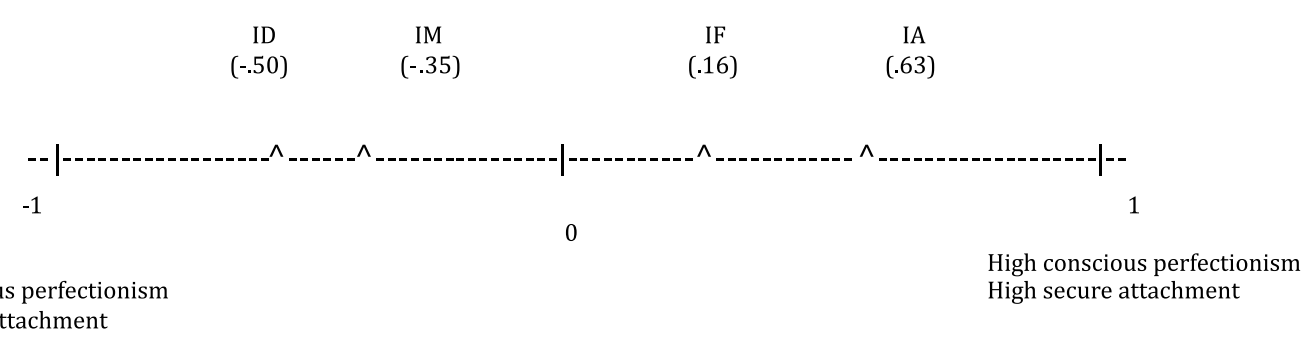

Low conscious perfectionis Low secure attachment

\section{Figure 2: Adaptive dimension of ego identity statuses.}

The second discriminant function is more heavily weighted on avoidance attachment, followed by self-evaluative perfectionism and ambivalent attachment styles. This dimension depicts maladaptive traits, feelings of unsecure and perceived pressure of high competition. These marks enable us to interpret it as a 'maladaptive dimension' (See Figure 3). 


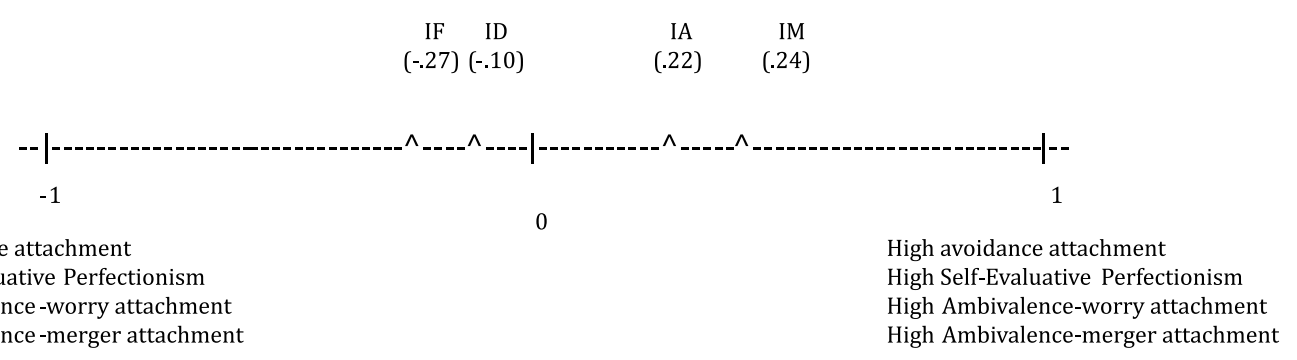

\section{Figure 3: Maladaptive dimension of ego identity statuses.}

Group centroids were examined to aid in identifying the nature of two discriminant functions. These centroids are mean values of discriminant function scores for all grouping variables. Larger centroid differences reflect better group discriminability. Univariate ANOVAs and subsequent post-hoc Tukey comparisons were conducted to examine the significance of discriminant function differences between the four identity statuses. The results show significant differences between centroids on "positive discriminant" function, except of centroids for identity moratorium and identity diffusion. In terms of 'positive dimension' identity achievement centroid score significantly differs from all other three identity centroid's scores $(\mathrm{F}(3.358)=20.21, \mathrm{p}=.00)$, with exception of the scores of identity moratorium and identity foreclosure. There is no significant difference between these two identity styles on first discriminant function scores (See Table 3)

\section{Table 3. Mean scores of canonical discriminant functions (Centroids) by identity status groups.}

\begin{tabular}{cccccc}
\hline & & \multicolumn{3}{c}{ Identity Status } \\
\hline Functions: & $\mathrm{IA}(\mathrm{n}=74)$ & $\mathrm{IA}(\mathrm{n}=74)$ & $\mathrm{IM}(\mathrm{n}=97)$ & $\mathrm{IF}(\mathrm{n}=124)$ & $\mathrm{F}(3.358)$ \\
(1) Positive discriminant & $.63 \mathrm{a}$ & $.63 \mathrm{a}$ & $-.35 \mathrm{~b}$ & $.16 \mathrm{c}$ & $20.21^{* * *}$ \\
(2) Negative discriminant & $.22 \mathrm{a}$ & $.22 \mathrm{a}$ & $.24 \mathrm{a}$ & $-.27 \mathrm{~b}$ & $6.20^{* * *}$ \\
\hline
\end{tabular}

Note: Means having the same subscript are not significantly different at $p<.01$ in the Tukey significant difference comparison ${ }^{* * *} p<.0001$

The Second dimension is only able to discriminate between identity foreclosure and all the rest of identity styles $(\mathrm{F}(3.358)=6.2, \mathrm{p}=.00)$, but there was no significant difference found between identity achievement, identity moratorium and identity diffusion.

The subject with an identity moratorium group earned the highest score for 'negative discriminant function' followed by identity achievement, identity diffusion and foreclosure.

\section{Discussion}

Firstly, descriptive analysis showed a gender effect on identity statuses: males tend to score higher on foreclosure than females. This can be explained by the following fact: In Georgian culture males get a pressure to be determined, and to make a choice in their life. Masculinity is associated with strong character, courage and ability to take responsibility on different aspects of life. Foreclosure is a protective mechanism in this circumstance: to meet the other expectations, males try to take and internalize values and interests that are defined by their families. In contrast, girls get high scores on the moratorium status than boys. The crisis associated with moratorium is possible to be more severe in girls: they try to explore different alternatives to choose the appropriate role. This is apparently the result of a number of reforms persuaded by the Georgian government with the goal to foster gender equality: traditional gender roles have been shifted and nowadays women and men have more or 
less equal opportunities than before. However, these changes become more demanding for women: in additional to traditional duties related to the household, women more rapidly try to pursue career and financially support their families. High scores on identity moratorium might reflect these tendencies: girls became more motivated to explore different possibilities to choose the appropriate role for themselves, because social environment has not guaranteed anymore already defined roles for them.

Differences between ego identity groups on attachment style, perfectionism and self-esteem have been explored. The study revealed that ego identity status differs by attachment style, perfectionism and self-esteem. Specifically, adolescents with identity achievement status have developed a secure attachment style, and high-level perfectionism than other ego identity status groups. Past studies suggest that perfectionism has not only positive impact, but negative impact too - it can lead to some personal and emotional problems: self-evaluative perfectionism (concern over mistakes, need for approval, rumination, perceived parental pressure) is greatly associated with neuroticism (Cruce, Pashak, Handal, Munz, \&Gfeller, 2012) and is mostly considered as a negative style of perfectionism. However, we find that perfectionism in ego identity context positively contributes to achieve identity status. Interestingly, achieved identity status group has a high level of perfectionism on both dimensions: conscientious and self-evaluative. This indicates that, striving for accomplishments and desire to success are more common to those who have achieved ego identity status.

The results of discriminant function analysis show that the four identity statuses can be different based on two underlined dimensions: adaptive and maladaptive. Adaptive dimension is comprised of two variables: secure attachment and conscientious perfectionism. Secure attachment is generally considered as a healthy and adaptive style of adjustment characterized by a high level of trust, high self-esteem and empathy, ability to pursue long term relationships and share feelings with other people. The parents of secure attachment children tend to be more attentive, responsive and react more quickly to children's demands. Conscientious perfectionism (organization, high standards for others, planfulness, and striving for excellence) is strongly correlated with general conscientiousness, and is regarded as adaptive or positive perfectionism. The study results suggest that both aspects together are capable to explain the variability of ego identity statuses. The lowest level of both perfectionism and secure attachment has an identity diffusion status followed by identity moratorium. Both identity statuses are negatively related with secure attachment and conscientious perfectionism. Identity Diffusion and Identity moratorium are both characterized with low level of commitment. These individuals have no commitment in particular roles, social values and goals. In contrast, adults with high level of secure attachment and conscientious perfectionism have either achieved or foreclosure identity statuses. These identity statuses have a high level of commitment and consequently those who get identity achievement or identity foreclosure status are devoted to their responsibilities, duties and are committed into the certain roles. Logically, we can hypothesize that secure attachment and conscientious perfectionism predict the level of commitment to the particular sets of goals and values. Without commitment, there is no resolution of identity crisis. Usually the starting point for teenagers to develop a sense of identity is diffusion followed by the moratorium, when there is a crisis, but no commitment. When they are faced with certain challenges related to defining their occupation, ideology, etc., they have to make important decisions and they became committed to the choice they have made. At this stage when commitment is evoked, identity is achieved. The study results lead us to consider secure attachment and sense of conscientious perfectionism as important contributors for developing the agency for commitment and devotion for the choices made by adolescents.

One possible explanation for why secure attachment is associated with commitment is that secure attachment is established when parents show responsibility towards their children, they serve as a model for them. Later children themselves become responsible for the choice they have made. Secure attachment helps to be devoted and faithful to their personal goals, values and important choices they made. Additionally, personal traits such as planfulness, organization, striving for excellence and high standards for others also amplify this process and help them to develop a sense of responsibility.

Maladaptive dimension is comprised of avoidance and ambivalent attachment (reluctant to be close to others, worry about perceived lack of love and care, suspicious of strangers). Avoidance attachment style is also associated with negative consequences such as low level of intimacy, inability to express emotions and feeling and inability to engage in stabile romantic or social relations because of low levels of self-compassion. For the same reason adults with avoidance attachment do not support 
their friends and partners in stressful situations. This set of negative features is capable to differentiate between identity styles: identity foreclosure has the lowest level on maladaptive dimension and significantly differs from other identity styles.

Adults with Identity foreclosure have a high level of commitment, but low level of exploration. They do not experience the identity crisis because mainly their parents make choices on their behalf and they just conform to their parents' expectations. Because of this conformism, they do not explore the options and possibilities for their roles, values and occupations. Our study shows that ambivalence and avoidance attachment styles categorize adults in two groups: the first is identity foreclosure group and the second is all other identity statuses. Identity foreclosure status group scores lowest on ambivalence or/ and avoidance attachment styles. It means that foreclosure identity status group adults who get the norms and values from their parents are less likely to have a negative attachment style. Adults, who don't experience rejection, prefer always parents over strangers, seek and receive comfort from parents and experience closeness to their parents, later are more prone to accept the rules and norms from them without reevaluation and criticism. It happens because negative attachment styles imply that parents do not have the main role for their children in early childhood. They did not provide their children with sufficient warmth and care and respectively, children do not feel protection from their parents. Undoubtedly, that leads to the negative consequences in late adulthood, and the less children display negative attachment styles the higher are chances for them to be adaptive and successful in adulthood. Nevertheless, as our study shows if there is no sign of negative attachment style, there is a high probability of conformism, criticism and low motivation for exploration. Even though we agree that avoidance and ambivalent attachment styles are less adaptive for children, in some ways they eliminate criticism, judgments, and motivation for exploration.

\section{Conclusions}

Overall, in this study, we found that gender has a significant effect on identity statuses of modern Georgian adolescents. Boys are more prone to accept and internalize the values and goals defined by their parents or other 'authorities' and follow their plans without personal exploration. The girls try to look for different options regarding their occupational and relational place to progress towards identity achievement.

Traditional cultural roles, beliefs and expectations force males to follow the family traditions, because in Georgian culture the view that males are the 'name successors' is still strong and therefore they are obliged to protect and pursue family values and traditions. In contrast, girls score higher on the moratorium status scale because the current reality is quite demanding for females: they have to succeed not only as housewives, but also as professionals.

The study result indicated that identity achievement, moratorium, foreclosure and diffusion could be understood based on two dimensions: adaptive vs. maladaptive. Secure attachment and conscientious perfectionism constitute adaptive dimension and adolescents with identity achievement have a high score there. Maladaptive dimension is comprised of avoidance, ambivalence attachment and self -evaluative perfectionism. All these factors decrease adaptivity of a person, make him/her more vulnerable and fragile. Identity foreclosure has the lowest position on this dimension that suggests that it is a more maladaptive identity status for adolescents.

The present study evidenced that there is difference in identity statuses between males and females and this pattern might be influenced by cultural roles and traditional views. Moreover, the study evidenced that secure attachment and conscious perfectionism are positively related to the most adaptive identity status: identity achievement. On the other hand, foreclosure identity, which is stronger in males, compared to females, is associated with maladaptive personal features and makes adolescence more vulnerable towards different life stressors.

\section{References}

Balistreri, E., Busch-Rossnagel, N. A., \&Geisinger, K. F. (1995). Development and preliminary validation of the Ego Identity Process Questionnaire. Journal of Adolescence, 18 (2), 179-192. 
Baumeister, R. F., \& Muraven, M. (1996). Identity as adaptation to social, cultural, and historical context. Journal of Adolescence, 19 (5), 405-416. doi:10.1006/jado.1996.0039.

Berman, A. M., Schwartz, S. J., Kurtines, W. M., \& Berman, S. L. (2001). The process of exploration in identity formation: the role of style and competence. Journal of Adolescence, 24 (4), 513-528. doi:10.1006/ jado.2001.0386.

Bosma, H. A., \& Kunnen, E. S. (2001). Determinants and mechanisms in ego identity development: A review and synthesis. Developmental Review, 21 (1), 39-66. doi:10.1006/drev.2000.0514

Carver, C. S. (1997). Adult attachment and personality: Converging evidence and a new measure. Personality and Social Psychology Bulletin, 23 (8), 865-883.

Cruce, S. E., Pashak, T. J., Handal, P. J., Munz, D. C., \& Gfeller, J. D. (2012). Conscientious perfectionism, self-evaluative perfectionism, and the five-factor model of personality traits. Personality and Individual Differences, 53 (3), 268-273. doi:10.1016/j.paid.2012.03.013.

Fleming, J., \& Elovson, A. (1988). The adult sources of self-esteem inventory. State University of California at Northridge.

Hill, R. W., Huelsman, T. J., Furr, R. M., Kibler, J., Vicente, B. B., \& Kennedy, C. (2004a). A new measure of perfectionism: The perfectionism inventory. Journal of Personality Assessment, 82 (1), 80-91.

Hill, R. W., Huelsman, T. J., Furr, R. M., Kibler, J., Vicente, B. B., \& Kennedy, C. (2004b). A new measure of perfectionism: The perfectionism inventory. Journal of Personality Assessment, 82 (1), 80-91. doi:10.1207/ s15327752jpa8201_13.

Kroger, J., \& Marcia, J. E. (2011). The identity statuses: Origins, meanings, and interpretations. In, Handbook of identity theory and research (pp. 31-53). Springer. Retrieved from http://link.springer.com/chapter/10.1007/978-1-4419-7988-9_2.

Marcia, J. E. (1966). Development and validation of ego-identity status. Journal of Personality and Social Psychology, 3 (5), 551.

Marcia, J. E., Waterman, A. S., Matteson, D. R., Archer, S. L., \& Orlofsky, J. L. (1993). Ego identity: A handbook for psychosocial research. Springer-Verlag, New York.

Schwartz, S. J., Beyers, W., Luyckx, K., Soenens, B., Zamboanga, B. L., Forthun, L. F., ... others. (2011). Examining the light and dark sides of emerging adults' identity: A study of identity status differences in positive and negative psychosocial functioning. Journal of Youth and Adolescence, 40 (7), 839-859.

Advised by Tetiana M. Shyriaieva, National University of Ostroh Academy, Ukraine

\begin{tabular}{cl}
\hline Maia Mestvirishvili & $\begin{array}{l}\text { Ph.D., Associate Professor, Faculty of Psychology, Tbilisi State University, Tbilisi, } \\
\text { Georgia. } \\
\text { Email: maia.mesvtirishvili@tsu.ge }\end{array}$ \\
\hline Natia Mestvirishvili & $\begin{array}{l}\text { MSc., Ph.D Student, Ivane Javakhishvili Tbilisi State University, Georgia } \\
\text { E-mail: Natia.mestvirishvili@gmail.com }\end{array}$ \\
\hline Khatuna Martskvishvili & $\begin{array}{l}\text { Ph.D., Assistant Professor, Faculty of Psychology, Tbilisi State University, } \\
\text { I. Chavchavadze av.\#1, 0179 Tbilisi, Georgia. }\end{array}$ \\
& Email: khatuna.martskvishvili@tsu.ge \\
\hline Luiza Arutinov & PhD., Associate Professor, Ivane Javakhishvili Tbilisi State University, Georgia. \\
& E-mail: b.arutinov@css.ge \\
\hline
\end{tabular}

